\title{
NTRK1 Gene Translocation
}

National Cancer Institute

\section{Source}

National Cancer Institute. NTRK1 Gene Translocation. NCI Thesaurus. Code C153061.

A cytogenetic abnormality that refers to any translocation involving the NTRK1 gene. 